\title{
Erratum: Public sector reforms and national development: A situational analysis of post-independent Nigeria
}

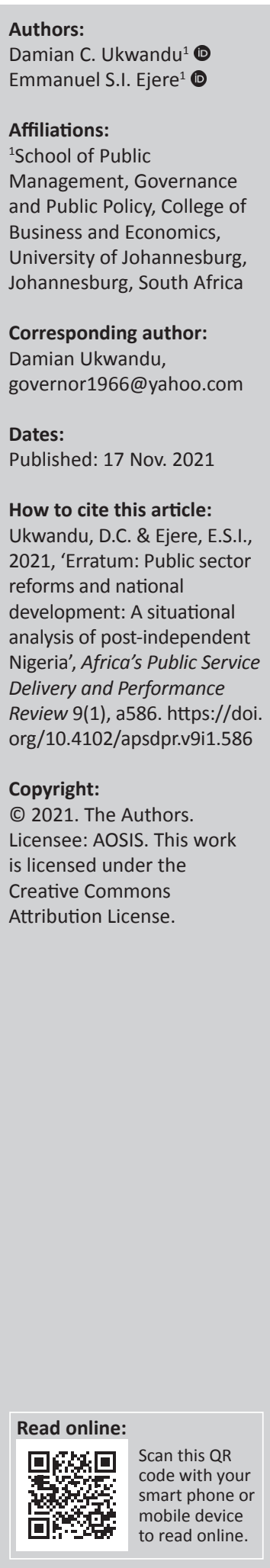

\section{Authors:}

\section{Affiliations:}

${ }^{1}$ School of Public

Management, Governance

Business and Economics,

University of Johannesburg,

Damian Ukwandu,

Dates:

Published: 17 Nov. 2021

Ejere, E.S.I.

reforms and national

development: A situational

analysis of post-independent

Nigeria', Africa's Public Service

Delivery and Performance

Review 9(1), a586. https://doi.

(1)

2021. The Authors.

Attribution License.
In the version of this article initially published, Ukwandu, D.C. \& Ijere, E.S., 2020, 'Public sector reforms and national development: A situational analysis of post-independent Nigeria', Africa's Public Service Delivery and Performance Review 8(1), a354. https:/ / doi.org/10.4102/apsdpr.v8i1.354, the second author's surname was spelled incorrectly. The correct spelling should be Ejere instead of Ijere.

This correction does not alter the study's findings of significance or overall interpretation of the study results. The publisher apologises for any inconvenience caused. 